\title{
O REGIME DOS COMPANHEIROS: \\ A ANOMIA SOBRE O REGIME DE BENS QUE REGULA A UNIÃO ESTÁVEL INQUINADA POR CAUSA SUSPENSIVA MATRIMONIAL
}

\author{
Danúbia Patrícia de Paiva ${ }^{1}$ \\ Daniel Monteiro Neves ${ }^{2}$
}

\begin{abstract}
Resumo
Este breve estudo tem como ponto de partida a ausência de norma legal positivada que preveja os efeitos das causas suspensivas matrimoniais no regime de bens da união estável. A partir dessa anomia, o trabalho busca teoricamente compreender a importância da previsão legal e, paralelamente, reconhecer os esforços jurisprudenciais e doutrinários para suprir a lacuna legal. Assim, importantes doutrinadores e relevantes decisões de tribunais superiores são trazidos para o trabalho, a fim de serem cotejados e deles extraírem-se conclusões para a obtenção mais segurança jurídica na configuração das uniões estáveis.
\end{abstract}

Palavras-chave: União estável; regime de bens; causas suspensivas; anomia; separação obrigatória.

\section{PROPERTY REGIME IN STABLE UNION (COMMON-LAW MARRIAGE): THE ANOMY ON THE MARITAL PROPERTY SYSTEM THAT REGULATES THE STABLE UNION (COMMON-LAW MARRIAGE) INQUINED FOR MATRIMONIAL SUSPENSIVE CAUSE}

\begin{abstract}
This work has as its starting point the absence of a positive legal norm that foresees the effects of matrimonial suspensive causes in the property regime of the stable union. From this anomie, the work theoretically seeks to understand the importance of legal prediction and, at the same time, recognize the jurisprudential and doctrinal efforts to fill the legal gap. Thus, important doctrinators and relevant decisions of higher courts are brought to work in order to be collated and draw conclusions for them to obtain more legal certainty in the configuration of stable unions.
\end{abstract}

Keywords: Stable union; property regime; suspensive causes; anomie; mandatory separation of the property system.

\footnotetext{
${ }^{1}$ Advogada e Professora. Doutora em Direito Processual Civil pela Universidade PUC/MINAS (2020). Mestre em Direito Público pela Universidade FUMEC (2015). Graduada em Direito pela UFMG (2007) e em Gestão Pública e Direito Administrativo pelo UNI/BH (2004). Possui Pós-graduação Lato Sensu em Direito Processual Civil pela UNIDERP (2010) e em Direito do Estado pela Universidade Cândido Mendes (2019). Professora na Escola Superior de Advocacia da OAB, na Universidade FUMEC e na Faculdade ALIS. Produtora de conteúdo sobre Direito Digital na página @ direitonoponto do Instagram.

${ }^{2}$ Doutor em Estudos Linguísticos - Linguística do Texto e do Discurso pela Universidade Federal de Minas Gerais - UFMG (2017). Mestre em Teoria Literária e Crítica da Cultura pela Universidade Federal de São João Del-Rei/MG (2013). Mestrando em Direito pela Universidade FUMEC, em Belo Horizonte/MG. Especialista em Direito Civil e Empresarial (2020), e Direito Notarial e Registral (2019), pela Faculdade Damásio (SP). Graduado em Direito pelo CESA (2010) e Letras pela UFSJ (2004). Professor de Língua Portuguesa e Literatura na EPCAR - Escola Preparatória de Cadetes do Ar. E-mail: dmneves@gmail.com
} 


\section{Introdução}

Os institutos do casamento e da união estável possuem naturezas diversas (um contrato sui generis versus uma típica situação de fato), mas o mesmo regime legal de bens, o da comunhão parcial de bens.

O Código Civil de 2002 dispõe que o casamento possui causas impeditivas (art. 1.521 do CC/02) e suspensivas (art. 1.523 do CC/02). As causas impeditivas recaem, de forma geral, sobre a união estável, impedindo sua constituição, conforme regra expressa do art. 1.723 do CC/02. O mesmo diploma civil, todavia, silencia a respeito da consequência das causas suspensivas para a união estável (BRASIL, 2002).

Assim, enquanto as causas suspensivas impõem o regime da separação obrigatória de bens para o casamento, na união estável elas não surtem efeito expresso em lei. Neste sentido, o art. 1.641 do CC/02 determina que a separação obrigatória de bens terá lugar, no casamento, sempre que: a) houver a ocorrência de causa suspensiva; b) um dos nubentes tiver mais do que setenta anos; e c) existir dependência de suprimento judicial para a realização do casamento (BRASIL, 2002).

Desses três fenômenos etiológicos, apenas o efeito do segundo para a união estável é trazido pela jurisprudência com posição remansosa. Já a consequência da ocorrência de causas suspensivas na união estável, além de descuidada pela lei, não é contemplada de forma pacífica pela jurisprudência, nem pela doutrina.

Alguns doutrinadores acreditam ser impossível determinar a separação obrigatória para união estável eivada por causa suspensiva, em virtude de a lei não prever a mudança do regime legal (comunhão parcial de bens), considerando que a supressão de direitos só poder se efetivar a partir de previsão expressa.

Por outro lado, há doutrina que defende a segurança jurídica das relações e que destaca a incoerência e possibilidade de "burla" caso, vigente uma causa suspensiva, o casamento pela comunhão parcial fosse vedado (como é) e, ao mesmo tempo, na união estável, com mesmo regime, fosse permitida.

Apesar disso, a regra é que, chegando ao Judiciário uma união estável caracterizada por causa suspensiva, o juiz decida pela separação obrigatória. Isso ocorre a fim de se garantir maior segurança jurídica. 
O problema jurídico, todavia, alicerça-se na lacuna provocada pela precariedade legislativa e, consequentemente, pela insegurança dos companheiros que não formalizam a união estável, ou mesmo por aquela revelada no balcão do tabelionato de notas diante da elaboração de uma escritura declaratória da união estável da qual se trata aqui.

Vale ressaltar que, embora este artigo não eleja a questão jurisprudencial como foco principal, há divergência nos julgados dos tribunais. A argumentação presente nas decisões judiciais pode conduzir, analisadas em conjunto, para um estudo fincado no obiter dictum ou, lado outro, na ratio decidendi. Uma análise da evolução jurisprudencial corroboraria a necessidade de uniformização diante do quadro apresentado.

O que fazer, afinal, para otimizar? Entre caminhos jurisprudenciais e legislativos, existe alguma orientação mais segura? Tais questões, dentre outras possíveis, não esgotadas no presente trabalho, mas se criam a partir do problema e do panorama delineados nestas linhas.

Portanto, a anomia referida não encontra, atualmente e a priori, uma solução capaz de eliminar a insegurança ou mesmo a possibilidade de atuações indesejavelmente contraditórias.

Ainda que esse elemento já seja tomado como justificativa suficiente, o atual posicionamento do STF sobre a constitucionalidade do art. 1.790 do CC/02 joga lume sobre os limites da equiparação entre casamento e união estável, mas não elimina em total as áreas obnubiladas em que os institutos ora se aproximam ou ora se afastam. Embora a questão da sucessão sejam distinta da questão tematizada aqui, há importantes doutrinadores sustentando uma equiparação total, ressalvada a questão da situação de fato e a situação contratualinstitucional já mencionadas.

A evolução jurisprudencial do STJ e do STF pode ser um norte seguro para estabelecer alguns parâmetros para distinção ou aproximação, pelo menos no aspecto que interessa neste trabalho, qual seja, os meios pelos quais se possa suprir uma lacuna legal e conferir segurança jurídica.

\section{A anomia quanto à incidência de causas suspensivas na união estável}

De acordo com a previsão legal e doutrinária, as normas que tratam do regime de bens da união estável foram cunhadas com referência na forma paradigmática do regime de 
bens do casamento. Contudo, pela natureza distinta dos institutos civis do direito de família, a adequação é imprescindível para a própria coerência interna e tratamento igualitário externo, ou seja, entre o casamento e a união estável deve haver normas que preservem e respeitem as diferenças, mas que, ao mesmo tempo, não estabeleçam hierarquias ou privilégios.

Desse modo, é preciso reconhecer causas que impossibilitem a constituição do casamento e da união estável e causas que, de outro viés, limitam um e outro com relação ao regime de bens. Quanto às causas impeditivas do casamento, conforme já se comentou em tópico anterior, o Código Civil sustenta o seguinte preceito:

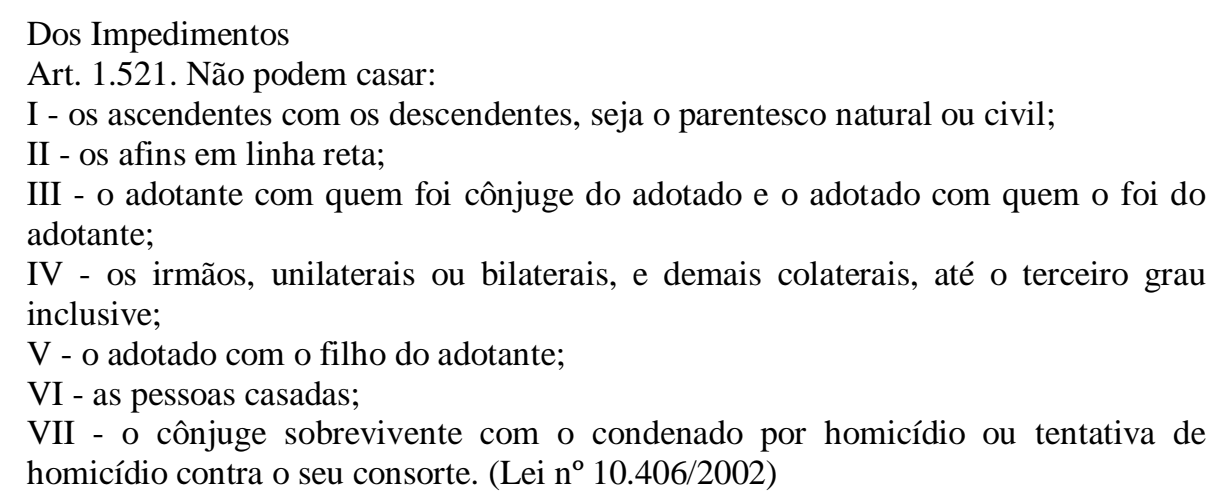

Os impedimentos são cláusulas de ordem pública e, aplicáveis irrestritivamente ao casamento, impossibilitam eventual consolidação da união matrimonial. Em outras palavras, pode-se afirmar que

\begin{abstract}
Os impedimentos relacionados pela lei têm caráter absoluto e são baseados no interesse público, porque têm em vista as causas relativas à instituição da família e à estabilidade social. O caráter público de tais impedimentos os torna impossíveis de serem supridos ou sanados, bem como torna nulo de pleno direito o casamento realizado com ofensa a qualquer deles. (PELUSO, 2018, p. 1556)
\end{abstract}

Próximas às causas suspensivas, mas significativamente distantes, residem as causas suspensivas do casamento, também abordadas en passant anteriormente. Não se trata, nesse caso, de normas que impossibilitam o reconhecimento do casamento, mas que limitam a autonomia privada dos contraentes em face da livre escolha do regime de bens. Segundo o Código Civil, são tais as causas suspensivas:

Art. 1.523. Não devem casar: 
I - o viúvo ou a viúva que tiver filho do cônjuge falecido, enquanto não fizer inventário dos bens do casal e der partilha aos herdeiros;

II - a viúva, ou a mulher cujo casamento se desfez por ser nulo ou ter sido anulado, até dez meses depois do começo da viuvez, ou da dissolução da sociedade conjugal; III - o divorciado, enquanto não houver sido homologada ou decidida a partilha dos bens do casal;

IV - o tutor ou o curador e os seus descendentes, ascendentes, irmãos, cunhados ou sobrinhos, com a pessoa tutelada ou curatelada, enquanto não cessar a tutela ou curatela, e não estiverem saldadas as respectivas contas.

Parágrafo único. É permitido aos nubentes solicitar ao juiz que não lhes sejam aplicadas as causas suspensivas previstas nos incisos I, III e IV deste artigo, provando-se a inexistência de prejuízo, respectivamente, para o herdeiro, para o excônjuge e para a pessoa tutelada ou curatelada; no caso do inciso II, a nubente deverá provar nascimento de filho, ou inexistência de gravidez, na fluência do prazo. (Lei $\left.n^{\circ} 10.406 / 2002\right)$

Se o Diploma Civil contempla com clareza tanto as causas impeditivas, quanto suspensivas do casamento, o mesmo já não se pode dizer em relação à aplicação das causas suspensivas e impeditivas do casamento à união estável. Nessa situação, o Código se resume a mencionar o que consta nos parágrafos $1^{\circ}$ e $2^{\circ}$ transcritos abaixo:

Art. 1.723. É reconhecida como entidade familiar a união estável entre o homem e a mulher, configurada na convivência pública, contínua e duradoura e estabelecida com o objetivo de constituição de família.

$\S 1^{\circ} \mathrm{A}$ união estável não se constituirá se ocorrerem os impedimentos do art. 1.521; não se aplicando a incidência do inciso VI no caso de a pessoa casada se achar separada de fato ou judicialmente.

$\S 2^{\circ}$ As causas suspensivas do art. 1.523 não impedirão a caracterização da união estável. (Lei n ${ }^{\circ}$ 10.406/2002)

Assim, com base no texto do Código Civil, podemos apresentar a seguinte tabela para fins didáticos: 


\begin{tabular}{|c|c|c|c|c|}
\hline \multicolumn{5}{|c|}{$\begin{array}{c}\text { Efeito das causas impeditivas e suspensivas matrimoniais } \\
\text { para o casamento e para a união estável }\end{array}$} \\
\hline Instituto & \multicolumn{2}{|c|}{ Casamento } & \multicolumn{2}{|c|}{ União estável } \\
\hline Causas & Impeditivas & Suspensivas & Impeditivas & Suspensivas \\
\hline Efeito & $\begin{array}{l}\text { O casamento é nulo de } \\
\text { pleno direito }\end{array}$ & $\begin{array}{l}\text { O casamento é válido, } \\
\text { mas deve ser constituído } \\
\text { sob o regime da } \\
\text { separação obrigatória de } \\
\text { bens }(\text { sanção do art. } \\
1.641, I)\end{array}$ & $\begin{array}{l}\text { A união estável é } \\
\text { nula de pleno } \\
\text { direito, em regra }\end{array}$ & $\begin{array}{l}\text { A união estável é } \\
\text { válida } \\
+ \\
\text { NENHUMA } \\
\text { MENÇÃO AO } \\
\text { REGIME DE } \\
\text { BENS (ou outra } \\
\text { sanção) }\end{array}$ \\
\hline \multirow{7}{*}{$\sum_{\substack{\infty \\
\infty}}^{\infty}$} & $\begin{array}{l}\text { 1. Ascendente com } \\
\text { descendente (natural } \\
\text { ou civil) }\end{array}$ & $\begin{array}{l}\text { 1. Viúvo(a) que tiver } \\
\text { filho do cônjuge falecido, } \\
\text { enquanto não fizer } \\
\text { inventário dos bens do } \\
\text { casal e der partilha aos } \\
\text { herdeiros * }\end{array}$ & $=$ casamento & SEM EFEITO \\
\hline & 2. Afins em linha reta & $\begin{array}{l}\text { 2. Viúva, ou mulher cujo } \\
\text { casamento se desfez por } \\
\text { ser nulo ou ter sido } \\
\text { anulado, até } 10 \text { meses } \\
\text { depois do começo da } \\
\text { viuvez, ou da dissolução } \\
\text { da sociedade conjugal ** }\end{array}$ & $=$ casamento & SEM EFEITO \\
\hline & $\begin{array}{l}\text { 3. Adotante com ex- } \\
\text { cônjuge do adotado / } \\
\text { Adotado com ex- } \\
\text { cônjuge do adotante }\end{array}$ & $\begin{array}{l}\text { 3. Divorciado, enquanto } \\
\text { não houver sido } \\
\text { homologada ou decidida } \\
\text { a partilha dos bens do } \\
\text { casal * }\end{array}$ & $=$ casamento & SEM EFEITO \\
\hline & $\begin{array}{l}\text { 4. Irmãos, unilaterais } \\
\text { ou bilaterais, e demais } \\
\text { colaterais, até o } \\
\text { terceiro grau, inclusive }\end{array}$ & \multirow[t]{4}{*}{$\begin{array}{l}\text { 4. Tutor ou curador e os } \\
\text { seus descendentes, } \\
\text { ascendentes, irmãos, } \\
\text { cunhados ou sobrinhos, } \\
\text { com a pessoa tutelada ou } \\
\text { curatelada, enquanto não } \\
\text { cessar a tutela ou } \\
\text { curatela, e não estiverem } \\
\text { saldadas as respectivas } \\
\text { contas* }\end{array}$} & $=$ casamento & SEM EFEITO \\
\hline & $\begin{array}{l}\text { 5. Adotado com filho } \\
\text { do adotante }\end{array}$ & & = casamento & SEM EFEITO \\
\hline & 6. Pessoas casadas & & $\begin{array}{l}\text { f casamento } \\
\text { (não se aplica o } \\
\text { impedimento se a } \\
\text { pessoa cada estiver } \\
\text { separada de fato } \\
\text { ou judicialmente) }\end{array}$ & SEM EFEITO \\
\hline & 7. Cônjuge & & $=$ casamento & SEM EFEITO \\
\hline
\end{tabular}




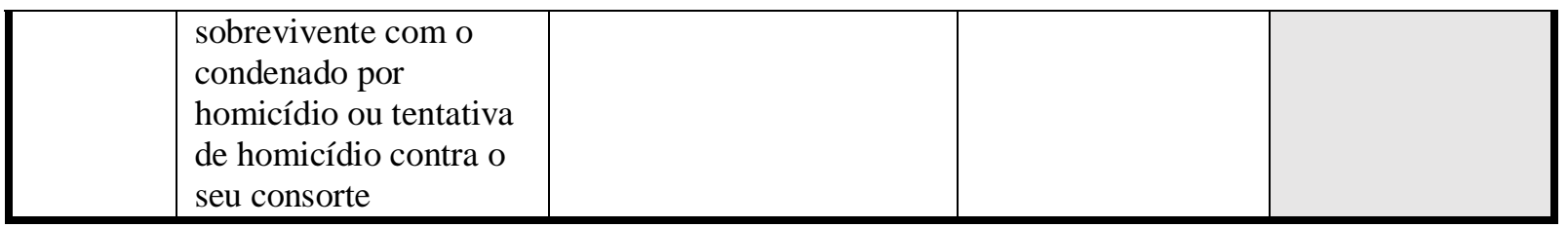

* Quanto às causas 1, 3 e 4, é permitido aos nubentes solicitar ao juiz que não lhes sejam aplicadas as causas suspensivas, provando-se a inexistência de prejuízo, respectivamente, para o herdeiro, para o ex-cônjuge e para a pessoa tutelada ou curatelada.

** Quanto à causa 2, a nubente deverá provar nascimento de filho, ou inexistência de gravidez, na fluência do prazo (parágrafo único do art. 1.523 do CC/02)

Quadro 1 - Elaborado pelos autores, a partir da Lei n ${ }^{\circ} 10.406 / 2002$

Quanto aos impedimentos para o matrimônio, sua relação com a ordem pública é, infere-se, a causa de serem também impedimentos para a constituição da união estável, como se vê, com clareza, no quadro. Há apenas uma das causas arroladas pelo 1.521 que ocasiona efeitos diferentes no casamento e na união estável: trata-se de pessoas já casadas. Nesse caso, há um impedimento sem exceção para que haja novo casamento; no entanto, se a pessoa casada estiver separada de fato ou judicialmente, ela poderá constituir união estável. Essa exceção foi inovação do atual Código Civil, que incorporou entendimento então consolidado pela jurisprudência e chamou para si o regramento sobre a união estável. Nesse diapasão,

\begin{abstract}
Alerte-se que admitiu o legislador a caracterização da união estável no caso de pessoa casada e separada de fato, ao declarar, no § 1o do art. 1.723, que "a união estável não se constituirá se ocorrerem os impedimentos do art. 1.521; não se aplicando a incidência do inciso VI no caso de a pessoa casada se achar separada de fato", ou seja, na hipótese de se comprovar que a pessoa vive um relacionamento consolidado com o novo companheiro, após a separação de fato, mesmo que não tenha sido desfeita a sociedade conjugal, ou mesmo o vínculo pelo divórcio ou anulação do casamento, ou, ainda, pela morte do cônjuge. Conclui-se que a União Estável não se baseia necessariamente no registro cartorial, mas sim no afeto e no intuito de constituir família. (PEREIRA, 2017, p. 694)
\end{abstract}

É útil frisar que, no caso da possibilidade de constituição de união estável por pessoas casadas, a separação de fato (ou judicial) é um requisito sine qua non. Assim, "na hipótese de o relacionamento com o outro companheiro ter começado quando ainda havia convivência com o cônjuge, somente após a separação de fato se dá o início da união estável, pois antes configurava concubinato." (idem, p. 694)

Se quanto aos impedimentos há apenas essa distinção pontual, a discriminação mais impactante ocorre, de fato, com as causas suspensivas. Como não existe norma estabelecendo as consequências das causas suspensivas matrimoniais para a união estável, supostamente é 
permitido que a união estável constituída sob uma de tais causas seja regrada por qualquer regime de bens. Por outro lado, há quem entenda serem aplicáveis à união estável as causas suspensivas do casamento. Na opinião de Cristiano Chaves de Faria e Nelson Rosenvald, há

uma instigante discussão a ser travada em relação ao regime de bens da união estável. Discute-se sobre a incidência ou não, das regras limitadoras da escolha do regime de bens no casamento, previstas no art. 1.641 da norma codificada.

Em linha de princípio, há de se concluir pela não incidência na união estável do regime de separação obrigatória de bens. A uma, porque não incidem as causas suspensivas na relação convivencial $(\mathrm{CC} / 02$, art. 1.523). A duas, porque não há necessidade de autorização judicial para constituí-la. A três, porque, em se tratando de norma limitadora de direitos, a interpretação da lei há de ser, necessariamente, restritiva. (FARIAS, 2019, p. 520)

Chaves e Rosenvald concluiriam o raciocínio alegando que "não incidiria, pois, na união estável, o regime da separação obrigatória de bens" (idem, p. 520). Em outra de suas obras, Cristiano Chaves de Farias seria até mais enfático, quando comenta a redação do art. 1.523. In verbis:

Inaplicabilidade à união estável. Diferentemente dos impedimentos matrimoniais, as causas suspensivas não são aplicáveis às uniões estáveis $\left(\mathrm{CC} / 02\right.$, art. $\left.1.723, \S 2^{\circ}\right)$, inexistindo imposição de regime de separação legal na família convivencial, que resta submetida ao regime de comunhão parcial, salvo disposição em contrário das partes. (DIDIER, 2017, p. 1.269)

Com efeito, Chaves e Rosenvald, quando falam das "regras limitadoras da escolha do regime de bens no casamento" tratam das causas suspensivas matrimoniais, mas não só. É que o art. 1641 determina que, ao lado de tais causas suspensivas, há um par de razões a ensejar a separação obrigatória de bens no casamento, conforme o artigo:

Art. 1.641. É obrigatório o regime da separação de bens no casamento:

I - das pessoas que o contraírem com inobservância das causas suspensivas da celebração do casamento;

II - da pessoa maior de 70 (setenta) anos;

III - de todos os que dependerem, para casar, de suprimento judicial. (Lei $\mathrm{n}^{\circ}$ $10.406 / 2002)$

Como se verifica, a literalidade do artigo 1.641 é direcionada ao casamento e, com efeito, o inciso III se refere exclusivamente ao casamento. A questão que se coloca é a aplicação dos incisos I e II à união estável. O primeiro atine às causas suspensivas e o 
segundo, à denominada "senilidade" como causas ensejadoras da separação obrigatória de bens. Para os doutrinadores supracitados nenhuma das duas causas é aplicável à união estável, pois, como disseram na citação colacionada, "em se tratando de norma limitadora de direitos, a interpretação da lei há de ser, necessariamente, restritiva”. Cristiano Chaves de Farias se posiciona assim em relação ao artigo 1.641:

Não aplicação à união estável. As limitações decorrentes do regime de separação obrigatória de bens não incidem na união estável, até porque toda regra que estabelece uma exceção merece interpretação restritiva. Assim, caso uma pessoa com mais de 70 anos de idade estabelecer uma união estável, ficará submetida às regras da comunhão parcial (CC/02, art. 1.725). (DIDIER, 2017, p. 1.406)

Esse entendimento, contudo, de não aplicação das causas suspensivas do casamento (e da senilidade) na união estável, está muito longe de ser pacífico. Afinal, a ausência de especificação sobre a relação entre as causas e a união estável poderia ser vista como uma anomia problemática para as uniões estáveis no decurso de sua existência, e a não aplicação da separação obrigatória, como clamam Chaves e Rosenvald, poderia representar um incoerente privilégio concedido à união estável. Na opinião de Rolf Madaleno,

\begin{abstract}
Não há qualquer explicação plausível para o tratamento discriminatório atribuído ao casamento pelo legislador no $\$ 2^{\circ}$ do artigo 1.723 do Código Civil, ao externar que as causas suspensivas do artigo 1.523 do Código Civil não impedirão a caracterização da união estável; contudo, impõe aos cônjuges a adoção obrigatória do regime da total separação de bens (CC/02, art. 1.641, inc. I), enquanto nenhuma sanção idêntica foi prevista para a eventual existência de precedente união estável, cujos protagonistas podem escolher livremente o regime de bens destinado a regulamentar os efeitos materiais de sua nova entidade estável, muito embora uma decisão do Superior Tribunal de Justiça tenha estendido a aplicação do artigo 1.641, inciso II, do Código Civil, impondo por senilidade o regime obrigatório da separação de bens à união estável. Não obstante este julgamento isolado, o artigo 1.725 do Código Civil segue estabelecendo na ausência de contrato escrito a adoção do regime legal da comunhão parcial nas uniões estáveis, sem qualquer referência ou restrição idêntica ou próxima das causas suspensivas do artigo 1.523 do Código Civil. (MADALENO, 2018, p. 1449)
\end{abstract}

Diante da crítica válida de Madaleno à diferenciação entre o casamento e a união estável no aspecto do regime diante da vigência de causa suspensiva, urge salientar que a

\footnotetext{
${ }^{3}$ O julgamento isolado a que alude o autor é tratado, com mais detalhes, no capítulo que contempla a jurisprudência sobre o tema. No capítulo, é a Decisão no 2. Trata-se do STJ - REsp: 1090722 SP 2008/02073502, Relator: Ministro MASSAMI UYEDA, Data de Julgamento: 02/03/2010, T3 - TERCEIRA TURMA, Data de Publicação: DJe 30/08/2010.
} 
exceção apontada pelo autor na jurisprudência tem relação exclusiva com a senilidade, a qual não integra o rol das causas suspensivas, mas emerge como uma causa específica a impor o regime da separação obrigatória de bens, nos termos do já comentado artigo 1.641 do Código Civil.

Logo, embora o efeito patrimonial das causas suspensivas e da senilidade (fato jurídico se ser a pessoa maior de setenta anos) seja o mesmo, não é certo, tecnicamente, dizer que a senilidade é uma das causas suspensivas, uma vez que estas encontram-se numerus clausus no 1.523, CC/02. Da mesma forma, não é certo dizer que a ausência de norma legal tratando das causas suspensivas e da senilidade como causas ensejadoras da imposição da separação obrigatória de bens na união estável tenha o mesmo tratamento na jurisprudência: como se verá no próximo capítulo, enquanto a situação da senilidade é pacífica na jurisprudência superior, a das causas suspensivas permanecem em suspenso. A doutrina, sempre profícua, a exemplo dos já citados autores, também trabalha diante - e em razão - da lacuna legal.

\section{Posições doutrinária e jurisprudencial diante da anomia e evolução}

Diante da ausência de norma que trate claramente do regime de bens da união estável constituída por companheiros afetados por uma das causas suspensivas matrimoniais (ou pela senilidade), surgem posições jurisprudenciais e doutrinárias à guisa de suplementação da anomia. Como se pôde verificar em citação anterior do jurista Rolf Madaleno, que fez referência ao REsp 1.090.722/SP, relatado pelo Min. Massami Uyeda, responsável pela aplicação do regime da separação obrigatória de bens a companheiro maior de setenta anos, os discursos da doutrina frequentemente imiscuem-se aos discursos da jurisprudência.

O que para este trabalho é denominado de anomia foi chamado por Chaves e Rosenvald de "instigante discussão" e por Carlos Roberto Gonçalves de uma "questão" que "merece destaque":

Merece destaque, ainda, a questão concernente à incidência ou não da regra da obrigatoriedade do regime da separação de bens para os companheiros em certas situações pessoais, como a de serem maiores de setenta anos, que obrigam os casados à adoção daquele regime $(\mathrm{CC} / 02$, art. 1.641, com a redação dada pela Lei n. 12.344/2010). (GONÇALVES, 2012, p. 1005) 
Gonçalves se refere especificamente ao art. 1.641, CC/02, comentado in fine no tópico anterior, que inclui, ao lado das causas suspensivas matrimoniais, a senilidade como causa de adoção do regime da separação obrigatória. Em seguida, o doutrinador associa-se a Caio Mário para defender a aplicação deste regime à senilidade, sob o argumento já mencionado, segundo o qual a ausência de aplicação conduziria a um "prestígio" da união estável em "detrimento" do casamento:

Entende Caio Mário da Silva Pereira que a aceitação da possibilidade de os companheiros idosos optarem, mediante contrato escrito, pelo regime da comunhão parcial de bens, previsto no art. 1.725 do Código Civil, significaria estarmos, "mais uma vez, prestigiando a união estável em detrimento do casamento, o que não parece ser o objetivo do legislador constitucional, ao incentivar a conversão da união estável em casamento. No nosso entender, deve-se aplicar aos companheiros maiores de 60 anos (atualmente, 70 anos) as mesmas limitações previstas para o casamento para os maiores desta idade: deve prevalecer o regime da separação legal de bens. A omissão do legislador na hipótese dos companheiros idosos criou flagrante conflito de interpretação.

Malgrado respeitáveis opiniões em contrário, constitui esse o melhor posicionamento a ser adotado, ante o comando constitucional emergente do art. 226, $\S 3^{\circ}$, da Carta Magna. (GONÇALVES, 2012, p. 2006)

"O melhor posicionamento a ser adotado", no entanto, não inclui as causas suspensivas, mas tão somente a senilidade. A seu turno, Guilherme Calmon Nogueira da Gama amplifica o entendimento para a defesa da separação obrigatória de bens na união estável em função de todas as causas que, na mesma proporção, ensejariam esse regime no casamento. Nogueira da Gama enfatiza que as pessoas as quais não podem escolher o regime de bens no casamento

\footnotetext{
"também não podem pactuar quanto aos bens adquiridos na constância da união extramatrimonial, pois, do contrário, haveria estímulo à existência de situações fundadas no companheirismo em detrimento do casamento, o que é vedado pela norma constitucional que prevê a conversão da união estável em casamento". Assim, aduz, "aos companheiros inseridos em qualquer uma das hipóteses previstas no art. 258, parágrafo único, suprarreferido (do CC/02/1916; CC/02/2002: art. 1.641), aplicar-se-á o regime da separação obrigatória de bens, tal como ocorre com o casamento". (NOGUEIRA DA GAMA, 2001, p. 345)
}

Como contraponto, no silêncio da anomia, da separação obrigatória de bens às uniões estáveis estabelecidas com pelo menos um dos companheiros sendo atingido por causa suspensiva matrimonial, engrossando o coro até então entoado por Cristiano Chaves e Nelson 
Rosenvald, soergue-se Flávio Tartuce, para quem, à medida que as causas suspensivas do casamento (art. 1.523, CC/02) não impedem a caracterização da união estável (art. 1723, § $2^{\circ}$, $\mathrm{CC} / 02$ ), tais causas

também não impõem o regime da separação obrigatória de bens. Não há imposição da separação obrigatória à união estável em nenhum dos casos previstos no art. 1.641 do mesmo Código Civil. Isso porque o art. 1.641 do CC/02 é norma restritiva da autonomia privada, que não admite interpretação extensiva ou por analogia. Ainda, se a regra gera restrição para o casamento, não existindo hierarquia entre as categorias familiares, não há razão para sua aplicação à união estável, pois são institutos diferentes tratados de maneiras distintas quanto aos direitos e deveres. Concluindo desse modo, com total razão: VELOSO, Zeno. Direito hereditário..., 2010, p. 171; LÔBO, Paulo. Famílias..., 2008, p. 161; SIMÃO, José Fernando. Efeitos..., 2010, p. 360; DIAS, Maria Berenice. Manual..., 5. ed., 2009, p. 170. (TARTUCE, 2017, p. 222-223)

O civilista Zeno Veloso, embora tenha tido opinião antiga mais próxima à equiparação dos institutos da união estável e do casamento no aspecto da necessidade da separação obrigatória de bens ${ }^{4}$, apresentou posteriormente um posicionamento firme quanto à inaplicabilidade do art. 1.641, CC/02, à união estável. Outrora, ele já havia se posicionado assim:

$\mathrm{O}$ art. 1.725 não se aplica aos companheiros se eles estiverem na mesma situação dos nubentes, consoante o art. 1.641, incisos I, II e III, aplicando-se a eles, por lógica, necessidade e similitude de situação, o disposto no aludido dispositivo, ou seja, a união estável fica submetida ao regime obrigatório da separação de bens. (VELOSO, 2002, p. 147)

Mais recentemente, no entanto, o entendimento de Veloso firmou-se no sentido oposto. Na obra "Direito Civil - Temas" (2018, o autor se manifesta assim quanto à temática:

$\mathrm{O}$ art. 1.641 do Código Civil brasileiro aponta os casos em que é obrigatório o regime de bens no casamento, sendo o mais importante - e controvertido - o do inciso II do citado art. 1.641, que menciona o casamento da pessoa maior de 70 (setenta) anos. O Superior Tribunal de Justiça - STJ mandou aplicar à união estável o regime da separação obrigatória se for pessoa idosa algum dos companheiros (cf. REsp 646.259/RS, $4^{\mathrm{a}}$ T., Rel. Min. Luís Felipe Salomão; REsp 1.090.722/SP $3^{\mathrm{a}}$ T., Rel Min. Massami Uyeda). Do ponto de vista doutrinário, manifestei-me contrário a esta extensão e da utilização de analogia para que o art. 1.641 do Código Civil, que é norma restritiva de direitos e de diminuição da autonomia privada, seja aplicável à união estável. Conforme o antiquíssimo brocado romano, Exceptiones sunt

\footnotetext{
${ }^{4}$ apud TARTUCE, 2017, p. 222
} 
strictissimae interpretationis $=$ Interpretam-se as exceções restritissimamente. (VELOSO, 2018, p. 303)

Vê-se que a inaplicabilidade da separação obrigatória para a união estável atingida pelas causas suspensivas matrimoniais encontra, como principal argumento jurídico, a noção segundo a qual as normas restritivas da autonomia privada não admitem interpretação extensiva ou por analogia. Com efeito, trata-se de um princípio basilar de hermenêutica jurídica, para cujos autores, a exemplo de Francisco Amaral, "as regras jurídicas de direito excepcional, as que impõem sanções ou concedem privilégios, as limitadoras da capacidade, não são suscetíveis de interpretação extensiva, exigindo, de regra, uma restritiva." (AMARAL, 2008, p. 123)

Tartuce desenvolve o seu raciocínio, na defesa da impossibilidade de extensão dos efeitos do art. 1.641, CC/02, à união estável, contemplando não apenas os doutrinadores supracitados, como também decisões relativamente recentes, na mesma direção. Segundo o autor,

\begin{abstract}
Nesse sentido, concluiu o Tribunal do Rio Grande do Sul que "Como a Lei estabelece regra específica para as relações econômicas entre os conviventes na união estável, e não contemplou a previsão do regime de separação obrigatória, não se pode interpretar ampliativamente a exceção prevista para a relação patrimonial própria do casamento" (TJRS, Apelação cível 70027870567, Porto Alegre, 7.a Câmara Cível, Rel. Des. Sérgio Fernando Silva de Vasconcellos Chaves, j. 08.07.2009, DOERS 16.07.2009, p. 35). (TARTUCE, 2017, p. 223)
\end{abstract}

Assim, a regra incluiria todas as excepcionalidades do art. 1.641, CC/02, que abrangem, como já se viu, as causas suspensivas matrimoniais e a senilidade. Nesse pensamento jurídico, como são normas restritivas de direitos, da autonomia privada, elas não poderiam ser aplicadas extensivamente à união estável, mas tão somente ao casamento.

Seguindo essa corrente, a título de exemplo, se uma pessoa que tem idade superior a 70 anos mantém união estável com outra, o regime desta será o da comunhão parcial, não havendo acordo entre as partes (art. 1.725 do $\mathrm{CC} / 02$ ). O contrato estabelecendo regime diverso será plenamente válido a par dessa forma de pensar juridicamente. (idem, p. 223)

Flávio Tartuce, todavia, dá relevo ao entendimento contrário ao seu, e enumera doutrina e jurisprudência que defendem-no: 
Em sentido contrário, vale aqui citar a posição de Regina Beatriz Tavares da Silva, para quem o art. 1.641 alcança não só o casamento como também a união estável (Novo Código..., 2004, p. 1.587). Seguindo a doutrinadora, o PL 699/2011, antigo $6.960 / 2002$, pretende resolver a questão criando um $\S 2^{\circ}$ para o art. 1.725 , nos seguintes termos: "\$ $2^{\circ}$ Aplica-se à união estável o regime da separação de bens nas hipóteses previstas no art. 1641, incisos I e II”.

Filiando-se também a esse último entendimento, comenta a promotora de justiça do Estado do Rio Grande do Norte Érica Verícia de Oliveira Canuto que:

'É de todo inaceitável que exista a sanção de obrigatoriedade do regime de separação de bens em certas situações para o casamento e não tenha a mesma correspondência à união estável. As duas situações (casamento e união estável) devem ser interpretadas de maneira igualitária. Ou se impõe também o regime da separação obrigatória de bens para a união estável nas mesmas situações previstas para o casamento (art. 1.641, CC/02/2002), ou não se aplica para o casamento a restrição ao direito de livre estipulação do regime patrimonial de bem, como se dá na união estável' (A mutabilidade..., 2005, p. 175).

O Superior Tribunal de Justiça tem seguido essa segunda corrente e aplicado o art. 1.641 do CC/02 à união estável diante da suposta equiparação da categoria familiar ao casamento (STJ, REsp 646.259/RS, 4.a Turma, Rel. Min. Luis Felipe Salomão, j. 22.06.2010). O entendimento foi repetido em julgado mais recente. Todavia, ao final, o acórdão traz a ressalva segundo a qual a norma traz atentado à dignidade do idoso, em clara contradição que parece indicar outro caminho no futuro. Vejamos a publicação, constante do Informativo n. 459 do STJ, de dezembro de 2010:

“União estável. Sexagenários. Regime. Bens. Trata o caso de definir se há necessidade da comprovação do esforço comum para a aquisição do patrimônio a ser partilhado, com a peculiaridade de que, no início da união estável reconhecida pelo tribunal a quo pelo período de 12 anos, um dos companheiros era sexagenário. A Turma, ao prosseguir o julgamento, por maioria, entendeu, entre outras questões, que, embora prevalecendo o entendimento do STJ de que o regime aplicável na união estável entre sexagenários é o da separação obrigatória de bens, segue esse regime temperado pela Súm. n. 377-STF, com a comunicação dos bens adquiridos onerosamente na constância da união, sendo presumido o esforço comum, o que equivale à aplicação do regime da comunhão parcial. Assim, consignou-se que, na hipótese, se o acórdão recorrido classificou como frutos dos bens particulares do excompanheiro aqueles adquiridos ao longo da união estável, e não como produto de bens eventualmente adquiridos antes do início da união, opera-se a comunicação desses frutos para fins de partilha. Observou-se que, nos dias de hoje, a restrição aos atos praticados por pessoas com idade igual ou superior a 60 anos representa ofensa ao princípio da dignidade da pessoa humana. Precedentes citados: REsp 915.297/MG, DJe 03.03.2009; EREsp 736.627/PR, DJe 1.0.07.2008; REsp 471.958/RS, DJe 18.02.2009, e REsp 1.090.722/SP, DJe 30.08.2010” (STJ, REsp 1.171.820/PR, Rel. originário Min. Sidnei Beneti, Rel. para o acórdão, Min. Nancy Andrighi, j. 07.12.2010). (idem, p. 223)

Portanto, se se pudesse esquadrinhar os posicionamentos doutrinários a respeito do tema, ter-se-ia aproximadamente o seguinte quadro:

Posicionamentos quanto à aplicação do regime de separação obrigatória de bens para a união estável na vigência de uma das causas do art. 1.641, CC/02 


\begin{tabular}{|c|c|c|}
\hline $\begin{array}{l}\text { Posicionamento } \\
\text { / entendimento: }\end{array}$ & $\begin{array}{l}\text { O regime da separação obrigatória } \\
\text { não é aplicável à união estável, mas } \\
\text { tão somente ao casamento }\end{array}$ & $\begin{array}{l}\text { O regime da separação obrigatória é } \\
\text { aplicável também à união estável }\end{array}$ \\
\hline $\begin{array}{l}\text { Principal } \\
\text { argumento: }\end{array}$ & $\begin{array}{l}\text { As causas presentes no art. } 1641 \text { se } \\
\text { referem somente ao casamento e, } \\
\text { assim, não podem ser aplicadas à união } \\
\text { estável, já que normas restritivas da } \\
\text { autonomia privada não podem ser } \\
\text { interpretadas extensivamente }\end{array}$ & $\begin{array}{l}\text { Apesar de as causas presentes no art. } \\
1641 \text { se referirem somente ao } \\
\text { casamento, a interpretação teleológica } \\
\text { leva à extensão dos efeitos à união } \\
\text { estável, uma vez que o contrário disso } \\
\text { equivaleria a preterir o casamento e } \\
\text { privilegiar a união estável }\end{array}$ \\
\hline \multirow{7}{*}{$\begin{array}{l}\text { Alguns } \\
\text { defensores: }\end{array}$} & Cristiano Chaves de Farias & Rolf Madaleno \\
\hline & Nelson Rosenvald & Carlos Roberto Gonçalves \\
\hline & Flávio Tartuce & Caio Mário da Silva Pereira \\
\hline & Zeno Veloso & Guilherme Calmon Nogueira da Gama \\
\hline & Paulo Lôbo * & Virgínia Arrais \\
\hline & José Fernando Simão * & Regina Beatriz Tavares da Silva \\
\hline & Maria Berenice Dias * & Érica Verícia Canuto de Oliveira \\
\hline Jurisprudência & TJRS & STJ \\
\hline
\end{tabular}

Quadro 2 - Elaborado pelos autores, a partir de consulta à doutrina e à jurisprudência

Quanto à jurisprudência, a investigação específica aqui será restrita à jurisprudência superior, notadamente no Tribunal da Cidadania, o STJ. O Tribunal, como se verá nas decisões colacionadas adiante, tem estabelecido uma coerência em relação à extensão à união estável da separação obrigatória no caso da senilidade, a despeito do silêncio quanto às causas suspensivas. Entretanto, se hoje é possível afirmar que há um posicionamento pacificamente reinante, houve oscilações anteriores que ainda inspiram certa prudência na aplicação das normas - ou sua ausência - no cotidiano jurídico das serventias notariais e registrais.

Tratando do tema, lembra Carlos Roberto Gonçalves que

O Superior Tribunal de Justiça, por sua vez, decidiu que, à semelhança do que ocorre com o casamento, na união estável é obrigatório o regime de separação de bens, no caso de companheiro com idade igual ou superior a 60 anos (atualmente 70 anos).

apud TARTUCE, 2017, p. 222 
É oportuno lembrar, a esta altura, que a jurisprudência tem proclamado, porém, que a referida restrição é incompatível com as cláusulas constitucionais de tutela da dignidade da pessoa humana, da igualdade jurídica e da intimidade, bem como com a garantia do justo processo da lei, tomado na acepção substantiva (CF, arts. $1^{\circ}$, III, e $5^{\circ}$, I, X e LIV).

Destarte, tanto no caso das uniões conjugais como nos de união estável, deve-se invocar, para afastar a aplicabilidade da aludida restrição, afronta ao inciso I do art. $5^{\circ}$ e ao $\S 5^{\circ}$ do art. 226, ambos da Constituição Federal, bem como ao princípio da dignidade da pessoa humana, consagrada no inciso III de seu art. $1^{\mathbf{o}}$ (...) (GONÇALVES, 2012, p. 1.034)

A citação ilustra, reiteradamente, que, no universo da jurisprudência, há histórica e naturalmente divergência. A seu despeito, a seguir seguem duas decisões do STJ dispostas cronologicamente, cuja sequência demonstram a evolução e a consolidação do entendimento naquela corte.

Decisão $n^{o} 1$ - Na decisão que segue (STJ - REsp: 1090722 SP 2008/0207350-2, Relator: Ministro MASSAMI UYEDA, Data de Julgamento: 02/03/2010, T3 - TERCEIRA TURMA, Data de Publicação: DJe 30/08/2010), o Ministro Massami Uyeda aplica o regime da separação obrigatória de bens à união estável em função da senilidade apontada pelo art. 1.641, II. É uma decisão paradigmática, citada com frequência na doutrina pátria.

RECURSO ESPECIAL - UNIÃO ESTÁVEL - APLICAÇÃO DO REGIME DA SEPARAÇÃO OBRIGATÓRIA DE BENS, EM RAZÃO DA SENILIDADE DE UM DOS CONSORTES, CONSTANTE DO ARTIGO 1641, II, DO CÓDIGO CIVIL, À UNIÃO ESTÁVEL - NECESSIDADE - COMPANHEIRO SUPÉRSTITE - PARTICIPAÇÃO NA SUCESSÃO DO COMPANHEIRO FALECIDO QUANTO AOS BENS ADQUIRIDOS NA CONSTÂNCIA DA UNIÃO ESTÁVEL OBSERVÂNCIA - INTELIGÊNCIA DO ARTIGO 1790, CC/02 - RECURSO PARCIALMENTE PROVIDO. I - O artigo 1725 do Código Civil preconiza que, na união estável, o regime de bens vigente é o da comunhão parcial. Contudo, referido preceito legal não encerra um comando absoluto, já que, além de conter inequívoca cláusula restritiva ("no que couber"), permite aos companheiros contratarem, por escrito, de forma diversa; II - A não extensão do regime da separação obrigatória de bens, em razão da senilidade do de cujus, constante do artigo 1641, II, do Código Civil, à união estável equivaleria, em tais situações, ao desestímulo ao casamento, o que, certamente, discrepa da finalidade arraigada no ordenamento jurídico nacional, o qual se propõe a facilitar a convolação da união estável em casamento, e não o contrário; IV Ressalte-se, contudo, que a aplicação de tal regime deve inequivocamente sofrer a contemporização do Enunciado n. 377/STF, pois os bens adquiridos na constância, no caso, da união estável, devem comunicar-se, independente da prova de que tais bens são provenientes do esforço comum, já que a solidariedade, inerente à vida comum do casal, por si só, é fator contributivo para a aquisição dos frutos na constância de tal convivência; V - Excluída a meação, nos termos postos na presente decisão, a companheira supérstite participará da sucessão do companheiro falecido em relação aos bens adquiridos onerosamente na constância da convivência (período 
que não se inicia com a declaração judicial que reconhece a união estável, mas, sim, com a efetiva convivência), em concorrência com os outros parentes sucessíveis (inciso III, do artigo 1790, CC/02). VI - Recurso parcialmente provido.

(STJ - REsp: 1090722 SP 2008/0207350-2, Relator: Ministro MASSAMI UYEDA, Data de Julgamento: 02/03/2010, T3 - TERCEIRA TURMA, Data de Publicação: DJe 30/08/2010, grifos nossos)

Decisão $n^{o} 2$ - A última decisão trazida (AgInt no REsp 1628268/DF, Rel. Ministro LÁZARO GUIMARÃES (DESEMBARGADOR CONVOCADO DO TRF 5 REGIÃO), QUARTA TURMA, julgado em 18/09/2018, DJe 27/09/2018), publicada no final do ano de 2018, evidencia a relativa estabilização do tema no STJ. No caso, as instâncias inferiores, restringindo a disposição do art. 1.641, II, apenas ao casamento, não aplicaram sua incidência à união estável, porém o ministro relator, reconhecendo o entendimento da Corte, deliberou pela incidência do regime da separação obrigatória de bens, já que a situação se refere à senilidade.

AGRAVO INTERNO NO RECURSO ESPECIAL. AÇÃO DE RECONHECIMENTO E DISSOLUÇÃO DE UNIÃO ESTÁVEL. COMPANHEIRO SEXAGENÁRIO. INDEFERIMENTO DE PROVA DOCUMENTAL PARA COMPROVAR A CAPACIDADE LABORATIVA E INDEPENDÊNCIA ECONÔMICA DA COMPANHEIRA. CERCEAMENTO DE DEVESA. OCORRÊNCIA. EFEITOS PATRIMONIAIS DA UNIÃO ESTÁVEL. REGIME DA SEPARAÇÃO TOTAL. APLICAÇÃ̃O DO ART. 1.641, II, DO CC/02. OPORTUNIDADE PARA COMPROVAR O ESFORÇO COMUM. RETORNO DOS AUTOS À ORIGEM. DECISÃO MANTIDA. RECURSO DESPROVIDO.

1. Não configura ofensa ao art. 535 do CPC/73 o fato de o col. Tribunal de origem, embora sem examinar individualmente cada um dos argumentos suscitados, adotar fundamentação contrária à pretensão da parte, suficiente para decidir integralmente a controvérsia.

2. Ocorre cerceamento de defesa quando, apesar de concluir pela desnecessidade da prova e afastar a ocorrência de prejuízo, confirma-se condenação que a prova indeferida visava afastar.

3. No que se refere aos efeitos patrimoniais decorrentes da existência da união estável, as instâncias ordinárias afastaram a aplicação da regra da separação obrigatória de bens, ao fundamento de que a disposição legal só se aplica ao casamento. Todavia, esta Corte tem entendimento de que estende-se à união estável a disposição do art. 1.641, II, do Código Civil, segundo o qual ao casamento de sexagenário, se homem, ou cinquentenária, se mulher, é imposto o regime de separação obrigatória de bens.

4. Por observar que a companheira não teve oportunidade de comprovar o esforço comum, deverá ser assegurado à autora o direito de comprovar o esforço na aquisição dos bens passíveis de serem compartilhados.

5. Devido ao parcial provimento do recurso, para reabertura da instrução, fica inviabilizado o pronto exame de todas as insurgências recursais, não sendo possível a aplicação do direito à espécie, nos termos da Súmula 456 do STF e do art. 1.034 do 
CPC/2015, quando se faz necessário o exame de matéria de fato ainda não devidamente esclarecida.

6. Agravo interno não provido.

(AgInt no REsp 1628268/DF, Rel. Ministro LÁZARO GUIMARÃES

(DESEMBARGADOR CONVOCADO DO TRF 5 ${ }^{\mathrm{a}}$ REGIÃO), QUARTA TURMA, julgado em 8/09/2018, DJe 27/09/2018, grifo nosso)

Em síntese, as decisões meramente exemplificativas confirmam alguns pressupostos aventados até o momento, neste trabalho, a saber: a) há uma anomia relevante quanto às normas restritivas da autonomia para o estabelecimento do regime de bens na união estável; b) tal anomia exige esforços doutrinários e jurisprudenciais; c) há, de forma geral, certa coerência na evolução das decisões do STJ; e c) mesmo os esforços jurisprudenciais são insuficientes, pois, além de se verificar insubsistências em algumas decisões, não se delibera sobre a incidência das causas suspensivas na união estável.

De todo modo, o panorama que se tem hoje pode ser representado em mais um quadro sintético, como o seguinte:

\begin{tabular}{|l|l|l|}
\hline \multirow{2}{*}{ Instituto } & \multicolumn{2}{c|}{ Causas impositivas da separação obrigatória de bens } \\
\cline { 2 - 3 } & Causas suspensivas & \multicolumn{1}{c|}{ Senilidade } \\
& & \\
\hline Casamento & Sim / Lei & Sim / Lei \\
\hline União estável & nihil & Sim / Jurisprudência \\
\hline
\end{tabular}

Quadro 3 - Elaborado pelos autores

\section{Conclusão}

As causas impositivas da separação obrigatória de bens são bem definidas pela lei no casamento, mas sua repercussão nas uniões estáveis ainda é conturbada.

O que se tem como definição é que, dentre as duas causas impositivas de tal regime (as causas suspensivas e a senilidade), apenas a segunda, a senilidade, encontra um posicionamento remansoso no STJ.

Esse entendimento, contudo, não sumulado, é passível de críticas, como as dirigidas por alguns doutrinadores, os quais, em suma, sustentam sua argumentação na noção representada pela máxima latina exceptiones sunt strictissimae interpretationis. 
A ideia de que as restrições, ou exceções, devem receber interpretação restrita, inadimitindo-se, por conseguinte, interpretação extensiva, parece ter um valor fundante para a hermenêutica jurídica - e um peso forte para qualquer argumentação.

Também por isso, dentro de uma possível e embrionária proposta de soluções para a problemática, poder-se-ia aventar prioritariamente a atualização legislativa, em secundarização da uniformização da jurisprudência.

O panorama atual reforça a tese de que é necessário um foco sobre as causas suspensivas e sua repercussão para a união estável.

O termo latino nihil, que pode ser traduzido como "nada", indica que não há lei definidora, como ocorre com o casamento, tampouco jurisprudência que auxilie na definição, o que se dá com a senilidade na união estável.

Há, pois, um vácuo, um silêncio eloquente, na situação da presença das causas suspensivas na união estável.

Isso causa um prejuízo significativo na segurança jurídica, palpável seja nos dilemas dos notários a lavrarem escrituras de união estável, seja nas demandas levadas ao Judiciário, principalmente quando da extinção das uniões estáveis estabelecidas sob um regime diverso da separação obrigatória, quando os companheiros se encontravam sob aqueles impedimentos matrimoniais.

As preocupações acadêmicas, então, devem se voltar a buscar estratégias a fim de conferir maior segurança jurídica na temática abordada, considerando inclusive um real debate entre todos, em prol da boa qualidade da prestação jurisdicional.

\section{Referências bibliográficas}

AMARAL, Francisco. Direito civil: introdução. Rio de Janeiro: Renovar, 2008.

ARRAIS, Virgínia. Aulas proferidas no Rio de Janeiro, RJ, durante o ano de 2018.

BARROSO, Luís Roberto. Diferentes, mas iguais: o reconhecimento jurídico das relações homoafetivas no Brasil (colaboradores: SOUZA NETO, Cláudio; MENDONÇA, Eduardo; DIZ, Nelson. In: Boletim Científico. ESMPU (Escola Superior do Ministério Público da União), Brasília, a. 6 - n. 22/23, p. 117-163 - jan./jun. 2007 a. 6 - n. 22/23, p. 117-163jan./jun. 2007. 
BRANDELLI, Leonardo. Teoria geral do direito notarial. Porto Alegre: Livraria do Advogado, 1998. p. 73-74

DIAS, Maria Berenice. Manual de direito das famílias. $6^{a}$ ed. São Paulo: Revista dos Tribunais, 2010.

DIDIER, Ricardo (org.). Código Civil para Concursos. Cristiano Chaves de Farias et. al. Salvador: Juspodivm, 2017.

DIP, Ricardo (org.). Introdução ao direito notarial e registral. Décio Antônio Erpen et. al. Porto Alegre: IRIB: Fabris, 2004.

FARIAS, Cristiano Chaves de et. al. Código Civil para concursos. Doutrina, jurisprudência e questões de concursos. Salvador: Juspodivm, 2017.

FARIAS, Cristiano Chaves de. Curso de direito civil: famílias. Cristiano Chaves de Farias, Nelson Rosenvald. 11. ed. rev. e atual. - Salvador: Juspodivm, 2019.

GAGLIANO, Pablo Stolze. Manual de direito civil; volume único. São Paulo: Saraiva Educação, 2018. (versão eletrônica, livro em formado para Kindle)

GONÇALVES, Carlos Roberto. Direito civil brasileiro, volume 6: direito de família. São Paulo: Saraiva, 2012.

KÜMPEL, Vitor Frederico et. al. Tratado Notarial e Registral vol. III. $1^{\text {a }}$ ed. São Paulo: YK editora, 2017.

LOUREIRO, Luiz Guilherme. Registros públicos: teoria e prática. 5. ed. São Paulo: Método, 2014.

MADALENO, Rolf. Manual de Direito de Família. $2^{\text {a }}$ ed. Rio de Janeiro: Forense, 2018.

NOGUEIRA DA GAMA, Guilherme Calmon. O companheirismo. 2. ed. São Paulo: Revista dos Tribunais, 2001.

PELUSO, Cezar (Org.). Código civil comentado: doutrina e jurisprudência. Cláudio Luiz Bueno de Godoy et. al. Barueri, SP: Manole, 2018.

PEREIRA, Caio Mário da Silva. Instituições de Direito Civil - Vol. V - Direito de Família. Rio de Janeiro: Forense, 2017.

SCHREIBER, Anderson et. al. Direito civil: diálogos entre a doutrina e a jurisprudência. Coord. Luís Felipe Salomão, Flávio Tartuce. 1ª ed. São Paulo, Atlas, 2018.

TARTUCE, Flávio. Direito Civil, v.5: Direito de Família. Rio de Janeiro: Forense, 2017. 
TARTUCE, Flávio. Manual de direito civil: volume único. 8. ed. rev, atual. e ampl. - Rio de Janeiro: Forense; São Paulo: Método, 2018.

VELOSO, Zeno. Código Civil comentado - v. XVII. São Paulo: Atlas, 2002.

VELOSO, Zeno. Direito Civil - Temas. Belém: Anoreg-PA, 2018. 